\title{
Implementation supervisory controller for hybrid wind microgrid system using adaptive neural MIMO model
}

- Ho Pham Huy Anh

- Nguyen Ngoc Son

Ho Chi Minh city University of Technology, VNU-HCM, Vietnam

- Tran Thien Huan

Ho Chi Minh city University of Technology and Education, Vietnam

(Manuscript Received on July 15, 2015, Manuscript Revised August 30, 2015)

\begin{abstract}
This paper investigates a novel forward adaptive neural model which is applied for modeling and implementing the supervisory controller of the hybrid wind microgrid system. The nonlinear features of the hybrid wind microgrid system are thoroughly modeled based on the adaptive identification process using experimental input-output training data. This paper proposes the novel

use of a back propagation (BP) algorithm to generate the adaptive neural-based supervisory controller for the hybrid wind microgrid system. The simulation results show that the proposed adaptive neuralbased supervisory controller trained by Back Propagation learning algorithm yields outstanding performance and perfect accuracy.
\end{abstract}

Keywords: hybrid wind microgrid system, back propagation learning algorithm (BP), adaptive neural-based supervisory controller, wind turbine, modeling and identification

\section{INTRODUCTION}

Hybrid renewable energy systems can be classified into two main types: grid-connected and standalone. The renewable energy sources can be PV or wind generators (or both), according to the availability of solar radiation or wind velocity (or both) at the system site. Batteries are often used as a backup source to supply the system when the renewable energy source is unavailable. Other backup sources can be used with or without batteries such as fuel cells (e.g. electrolysers, supercapacitors and flywheel energy storage). Diesel generators could be used as secondary sources of renewable energy. The standalone system might provide dc power, ac power, or both $\mathrm{dc}$ and ac power [1-3]. The grid-connected systems can work on standalone mode when the utility grid is unavailable. In grid-connected systems, the utility grid is a secondary source. For the most part, fuel cells and diesel generators are not used with such grid-connected systems. The supervisory controllers manage the power according to the type and different components of the system. The supervisory controllers could be 
divided generally to two kinds; conventionalbased and artificial intelligence-based methods.

A small-scale hybrid PV-Wind generation system with batteries works only in standalone mode as proposed in [6]. The power conditioning unit is limited to maximize the output power from both the wind and the PV generators to the batteries. The charging and discharging methods of batteries, over power ratings and load management, are not taken into account in this system. A design of a supervisory controller based on a sliding mode control is presented in reference [4]. The system is a standalone hybrid PV-Wind generation system. For the design of such a supervisory controller, the wind generator plays the role of the main generator while the solar generator is a secondary power source. The system has three modes of operation: in the first mode, the wind generator is regulated to supply the system while the PV generator is OFF. In the second mode, the wind power is maximized and the PV power is regulated. Both PV and wind are maximized in the last mode. In the proposed control strategy, the battery state of charge is not taken into account. Furthermore, the wind power regulation strategy is not explained. A wind generation system with storage batteries is controlled to work in both grid and standalone operation modes discussed in this chapter [1]. The supervisory controller in this system is designed to provide smooth transitions between the modes. Furthermore, it controls the inverter, providing fault ride through to limit the output current during utility grid side faults. This fault ride through strategy is explained in reference [5].

The supervisory controller of a standalone hybrid Wind-PV-fuel cell (FC) energy system is proposed in [7-9]. Every source is connected to the ac bus bar via an inverter to supply the load. The FC-electrolyzer combination is used as a backup and long-term storage system. The battery bank is used in the system as a short-time backup to supply the transient power. At any given time, the supervisory controller controls any excess wind-PV-generated power to be supplied to the electrolyser. The hydrogen, which is delivered to the hydrogen storage tanks by a gas compressor, is consequently generated. If the generated power is less than the load demand, the FC stack begins to produce energy for the load using hydrogen from the storage tanks. A steady state model was used in the papers with no dynamical results. This study demonstrates that the low voltage distribution network is supervised to optimize energy flow and control power quality [10]. This kind of system is supplied by renewable energy sources, diesel generators, and energy storage backups. The system is controlled, according to international power quality standards. The algorithm is universal and adapts its control variables. This controller is concerned with the utility grid not with controlling the local generators. A power management program is proposed in reference [11] for a grid-connected wind-generated system with energy storage. The energy storage is controlled to smooth the power output of the energy generation system to the grid. The average wind velocity is forecast for the next hour and then the energy storage output is managed according to the forecast value. A new scheme of a standalone hybrid PV-Wind system with batteries is proposed in [12]. The PV is directly connected in parallel with the batteries to supply the ac load through a three phase inverter which is connected from the other side to a wind generator. The power management strategy is simplified in this configuration as the batteries act as a constant voltage load line which charges both ways by the PV and the wind generators. A dump load can be switched on with batteries fully charged but the batteries are later disconnected to prevent overcharging. One of the drawbacks is that there is no ability in this scheme to provide PV or wind generators control. Furthermore, the 
atteries' charging and discharging is not fully controlled.

Recently, there were many researches focus on artificial intelligence-based methods applied to supervisory control of hybrid microgrid systems. A standalone system with hybrid PV-diesel power generators and flywheel backup energy storage system is proposed in [13]. A pump is used as an auxiliary load to absorb the extra power from the system. A fuzzy logic supervisory controller is proposed to manage the power from the generators to the load. According to the generated PV power and the rotor speed of the flywheel, the fuzzy controller adjusts the references for the diesel generator output power and the pump demand. A fuzzy logic supervisor is proposed also in reference [14] for a grid-connected wind generated system. The same system used in the last reference is used in this reference [15] with the exception that there is a flywheel controlled by a fuzzy supervisor to smooth the output power of the wind generator. A storage capacitor could be used also in the same manner [16]. In a microgrid system [17], the PV generators could be used to remove frequency deviations using fuzzy supervisory controller. In reference [18], the fuzzy supervisor controls the pitch angle of a fixed speed wind generator. Authors in [19] proposed a neural-based supervisory controller manages the power in a PV standalone system with batteries. The drawback of all these supervisory controllers relate to the lack of precision and performance in their realtime operation.

This paper proposes the novel use of adaptive neural MIMO model to generate the supervisory controller for the hybrid wind microgrid systems. The Back Propagation (BP) learning algorithm is used to process the experimental input-output data that is measured from the optimal desired operation of the hybrid wind microgrid systems as to optimize all nonlinear and dynamic features of this system.
The rest of the paper is organized as follows. Section II introduces the implementation of supervisory controller in hybrid wind microgrid systems. Section III presents the novel adaptive neural MIMO model using for the implementation of supervisory controller in hybrid microgrid systems. The results from the proposed adaptive neural-based supervisory controller are presented in Section IV. Finally, Section V contains the concluding remarks.

\section{PROPOSED NEURAL SUPERVISORY CONTROL OF THE HYBRID MICROGRID SYSTEM}

We consider an implementation a supervisory controller for the hybrid microgrid systems illustrated in fig.1. From this figure, the neural NARX-based supervisory controller regulates the power of the wind generator according to the change of the wind turbine and load powers.

In figure 1, proposed neural NARX controller plays the role of a supervisory monitor. Based on the power of the wind energy system and the consumed power of the load which were considered as input values, the adaptive neural supervisor will appropriately and auto-tuningly switches the $S_{1}, S_{2}$ and $S_{3}$ as to ensure the most efficient operation for the hybrid microgrid systems.

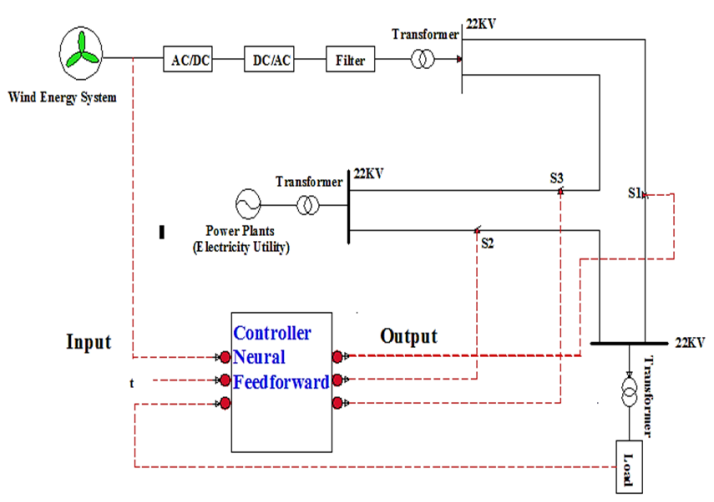

Figure 1. Schematic of a supervisory controller for the hybrid wind-turbine microgrid systems 
The BP algorithm optimally generates the appropriate neural weightings to perfectly characterize the features of the supervisory controller for the hybrid wind microgrid systems. These good obtained results are due to proposed adaptive neural MIMO model combines the extraordinary approximating capability of the neural system with the powerful predictive and adaptive potentiality of the nonlinear ARX structure that is implied in the proposed adaptive neural-based model. Consequently, the proposed method of the generation of the adaptive supervisory controller for the hybrid microgrid systems has successfully modeled the nonlinear features of the desired operation of the hybrid wind microgrid system with good performance.

\section{ADAPTIVE NEURAL MIMO MODEL FOR SUPERVISORY CONTROL THE HYBRID WIND MICROGRID SYSTEM}

The adaptive forward Neural MIMO model used in this paper is a combination between the Multi-Layer Perceptron Neural Networks (MLPNN) structure and the Auto-Regressive with eXogenous input (ARX) model. Due to this combination, adaptive forward Neural MIMO model possesses both of powerful universal approximating feature from MLPNN structure and strong predictive feature from nonlinear ARX model.

A fully connected 3-layer feed-forward MLPnetwork with $n$ inputs, $q$ hidden units (also called "nodes" or "neurons"), and $m$ outputs units is shown in Fig. 2.

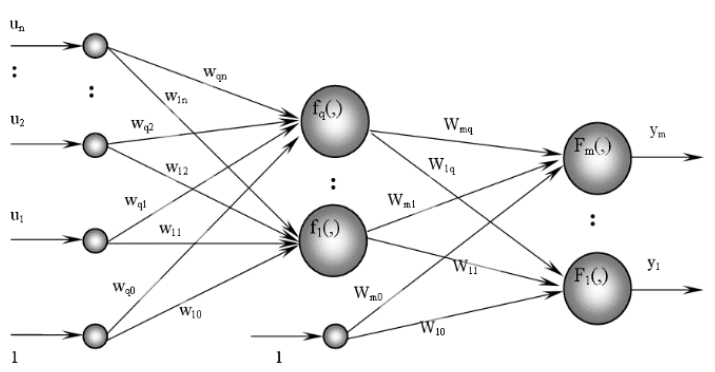

Figure 2. Structure of feed-forward MLPNN
In Fig. $2, w_{10}, . ., w_{q 0}$ and $W_{10}, . ., W_{m 0}$ are weighting values of Bias neurons of Input Layer and Hidden Layer respectively.

Forwardly we consider an Auto-Regressive with eXogenous input (ARX) model with noisy input, which can be described as

$A\left(q^{-1}\right) y(t)=B\left(q^{-1}\right) u(t-T)+C\left(q^{-1}\right) e(t)$

(1)

$$
\begin{aligned}
& \text { with } A\left(q^{-1}\right)=1+a_{1} q^{-1}+a_{2} q^{-2} \\
& \qquad B\left(q^{-1}\right)=b_{1}+b_{2} q^{-1} \\
& C\left(q^{-1}\right)=c_{1}+c_{2} q^{-1}+c_{3} q^{-2} \text { where } e(t) \text { is the white }
\end{aligned}
$$

noise sequence with zero mean and unit variance; $u(t)$ and $y(t)$ are input and output of system respectively; $q$ is the shift operator and $T$ is the time delay.

From equation (1), not considering the noise component $e(t)$, we have the general form of the discrete ARX model in $\mathrm{z}$-domain (with the time delay $T=n_{k}=1$ )

$$
\frac{y\left(z^{-1}\right)}{u\left(z^{-1}\right)}=\frac{b_{1} z^{-1}+b_{2} z^{-2}+\ldots+b_{n_{b}} z^{-n_{b}}}{1+a_{1} z^{-1}+a_{2} z^{-2}+\ldots+a_{n_{a}} z^{-n_{a}}}
$$

in which $n_{a}$ and $n_{b}$ are the order of output $y\left(z^{-1}\right)$ and input $u\left(z^{-1}\right)$ respectively.

We investigate the potentiality of various simple adaptive neural MIMO models in order to exploit them in modeling, identification and control as well. The adaptive neural-based supervisory controller of the hybrid wind microgrid system is investigated. Thus, by embedding a 3-layer MLPNN (with number of neurons of hidden layer equal 5) in a $1^{\text {st }}$ order ARX model with its characteristic equation induced from Figure 1, as follows:

$$
\begin{aligned}
& s_{1} h a t(k)=b_{11} p_{w}(k)+b_{12} p_{L}(k)-a_{11} s_{1}(k-1)-a_{12} s_{2}(k-1)-a_{13} s_{3}(k-1) \\
& s_{2} h a t(k)=b_{21} p_{W}(k)+b_{22} p_{L}(k)-a_{21} s_{1}(k-1)-a_{22} s_{2}(k-1)-a_{23} s_{3}(k-1) \\
& s_{3} h a t(k)=b_{31} p_{W}(k)+b_{32} p_{L}(k)-a_{31} s_{1}(k-1)-a_{22} s_{2}(k-1)-a_{33} s_{3}(k-1)
\end{aligned}
$$


We will design the proposed adaptive neuralbased supervisory controller of the hybrid PV microgrid system (with $n_{a}=1, n_{b}=1, n_{k}=1$ ) with 5 inputs (including two input values $p w(k), p l(k)$ and three recurrent delayed output values $s_{I}(k-1)$, $\left.s_{2}(k-1), s_{3}(k-1)\right)$ and three output values $s_{\text {lhat }}(k)$, $s_{2 h a t}(k)$ and $s_{3 h a t}(k)$. We remember that two input values $p w(k), p l(k)$, representing the two power inputs $[\mathrm{MW}]$ of the wind turbine and the load, respectively and the three output values $s_{\text {lhat }}(k)$, $s_{2 h a t}(k)$ and $s_{3 h a t}(k)$ representing the responding switching output of the adaptive neural-based supervisory controller. Its structure is shown in Fig. 3.

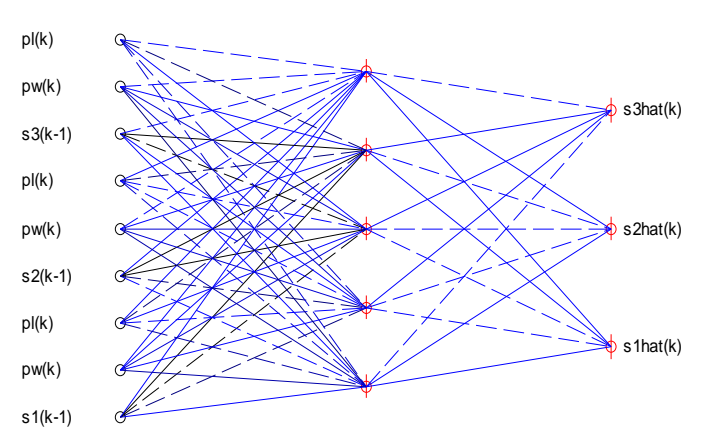

Fig.3. Model structure of the adaptive neuralbased supervisory controller of the hybrid windturbine microgrid system

By this way, the fifteen parameters $a_{11}, a_{12}$, $a_{13}, b_{11}, b_{12}, a_{21}, a_{22}, a_{23}, b_{21}, b_{22}, a_{31}, a_{32}, a_{33}, b_{31}$, $b_{32}$ of the ARX structure of three switching output variables $s_{\text {lhat }}(t), s_{2 h a t}(t)$ and $s_{3 h a t}(t)$, respectively, now become adaptively nonlinear and will be determined from the weighting values $W_{i j}$ and $w_{j l}$ of the proposed adaptive Neural MIMO NARX model.

The prediction error approach, which is the strategy applied here, is based on the introduction of a measure of closeness in terms of a mean sum of square error (MSSE) criterion:

$$
E_{N}\left(\theta, Z^{N}\right)=\frac{1}{2 N} \sum_{t=1}^{N}[y(t)-\hat{y}(t \mid \theta)]^{T}[y(t)-\hat{y}(t \mid \theta)]
$$

Based on the conventional error BackPropagation (BP) training algorithms, the weighting value is calculated as follows:

$$
W(k+1)=W(k)-\lambda \frac{\partial E(W(k))}{\partial W(k)}
$$

with $k$ is $k^{\text {th }}$ iterative step of calculation and $\lambda$ is learning rate which is often chosen as a small constant value.

Concretely, the weights $W_{i j}$ and $w_{j l}$ of neural MIMO NARX are then updated as:

$$
\begin{aligned}
& W_{i j}(k+1)=W_{i j}(k)+\Delta W_{i j}(k+1) \\
& \Delta W_{i j}(k+1)=\lambda \cdot \delta_{i} \cdot O_{j} \\
& \delta_{i}=\hat{y}_{i}\left(1-\hat{y}_{i}\right)\left(y_{i}-\hat{y}_{i}\right)
\end{aligned}
$$

(6)

with $\delta_{i}$ is search direction value of $i^{\text {th }}$ neuron of output layer $(i=[1 \rightarrow m]) ; O_{j}$ is the output value of $j^{\text {th }}$ neuron of hidden layer $(j=[1 \rightarrow q]) ; y_{i}$ and $\hat{y}_{i}$ are truly real output and predicted output of $i^{\text {th }}$ neuron of output layer $(i=[1 \rightarrow m])$, and

$$
\begin{aligned}
& w_{j l}(k+1)=w_{j l}(k)+\Delta w_{j l}(k+1) \\
& \Delta w_{j l}(k+1)=\lambda \cdot \delta_{j} \cdot u_{l} \\
& \delta_{j}=O_{j}\left(1-O_{j}\right) \sum_{i=1}^{m} \delta_{i} W_{i j}
\end{aligned}
$$

in which $\delta_{j}$ is search direction value of $j^{\text {th }}$ neuron of hidden layer $(j=[1 \longrightarrow q]) ; O_{j}$ is the output value of $j^{\text {th }}$ neuron of hidden layer $(j=[1 \rightarrow q]) ; u_{l}$ is input of $l^{\text {th }}$ neuron of input layer $(l=[1 \rightarrow n])$.

\section{NEURAL MIMO MODEL FOR THE SUPERVISORY CONTROL OF THE HYBRID WIND MICROGRID SYSTEM}

In general, the procedure which must be executed when attempting to identify a dynamical system consists of four basic steps.

- STEP 1 (Getting Training Data)

- $\quad$ STEP 2 (Select Model Structure)

- STEP 3 (Estimate Model)

- STEP 4 (Validate Model) 
In Step 1, the identification procedure is based on experimental input-output data values measured from the desired input-output of the adaptive neural-based supervisory controller of the hybrid wind-turbine microgrid system. The two input values $p w(k), p l(k)$, representing the two power inputs $[\mathrm{MW}]$ of the wind turbine and the load and the three desired referential output values $s_{\text {lhat }}(k), \quad s_{\text {2hat }}(k)$ and $s_{3 h a t}(k)$ representing the responding switching output of the adaptive neural-based supervisory controller.

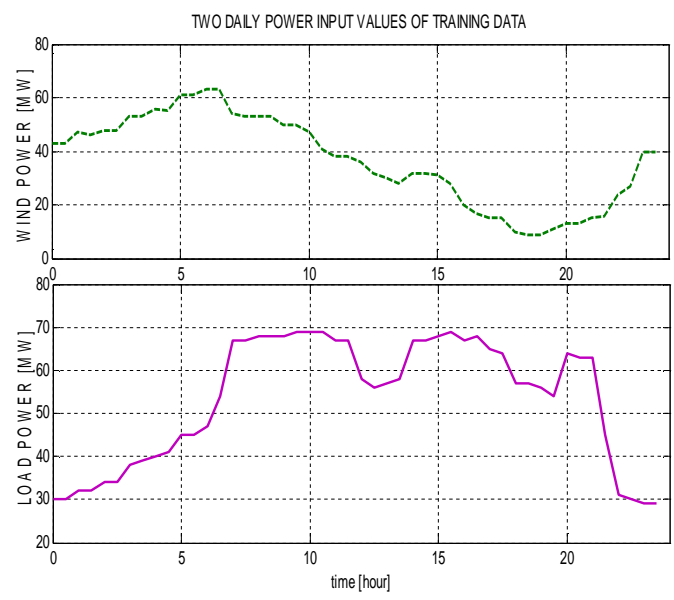

Fig.4a Two power input signals $p w(k), p l(k)$ of training data for identification process THREE SWITCHING OUTPUT VALUES OF TRAINING DATA
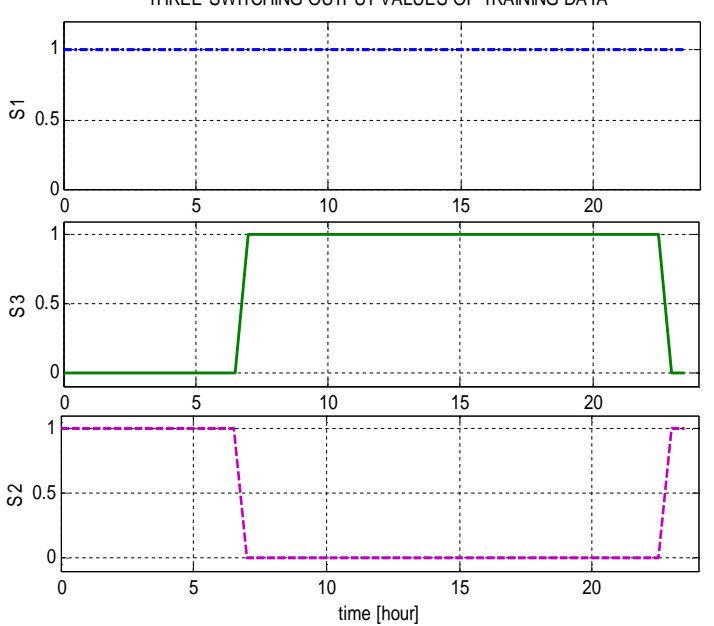

Fig.4b Three switching output signals of training data for identification process
Figure $4 \mathrm{a}$ and Figure $4 \mathrm{~b}$ presents the collected input-output data composes of the two input signals $p w(k), p l(k)$ applied to the neural-based supervisory controller of the hybrid wind-turbine microgrid system and the referential output values $s_{\text {Ihat }}(k), s_{2 h a t}(k)$ and $s_{3 h a t}(k)$.

Back Propagation (BP) learning algorithm based on the error between the $\left(s_{1}, s_{2}, s_{3}, s_{4}, s_{5}\right)$ reference switching outputs and the responding ( $\left.s_{\text {lhat }}, s_{2 h a t}, s_{3 h a t}, s_{4 h a t}, s_{5 h a t}\right)$ switching outputs of adaptive neural MIMO NARX model to update the weights of proposed neural MIMO NARX supervisory controller. Fig.5 illustrates identification scheme of the neural MIMO NARX supervisory controller using proposed Neural MIMO NARX model for microgrid wind system.

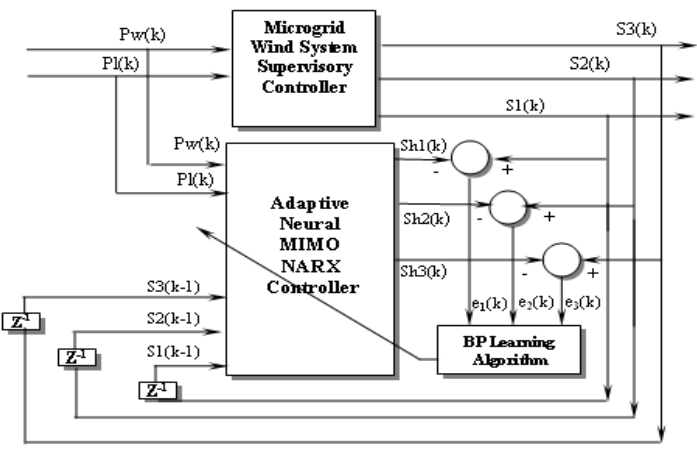

Fig.5 Identification scheme of the neural-based supervisory controller using proposed adaptive Neural MIMO NARX model

The second step relates to selecting the model structure. The block diagram in Fig.5c illustrates the identification scheme of the proposed intelligent model. The proposed adaptive neural MIMO NARX model structure was attempted. Its model structure was presented in Fig. 3.

The third step estimates values for the trained adaptive Neural NARX model. The optimal fitness value to use for the BP-based optimization and identification process is calculated. The estimation result is presented in Fig. 6. This figure represent the fitness convergence values of the 
proposed forward kinematics of the industrial robot arm FNMN system which correspond to adaptive neural NARX identified and optimized with Back Propagation (BP) learning algorithm. The fitness value of the proposed adaptive neuralbased supervisory controller identification produces an excellent global optimal value (equal to 0.000036 ).

These good results are due to how the proposed model combines the extraordinary approximating capability of the neural system with the powerful predictive and adaptive potentiality of the nonlinear NARX structure that is implied in the adaptive neural MIMO NARX model. Consequently, the BP-based forward kinematics of the industrial robot arm FNMN model addresses all of the nonlinear features of the forward kinematics of the industrial robot arm system that are implied in the five responding output switching signals $(s 1, s 2, s 3, s 4, s 5)$ from three power input values $(p w(k), p s(k), p l(k))$.

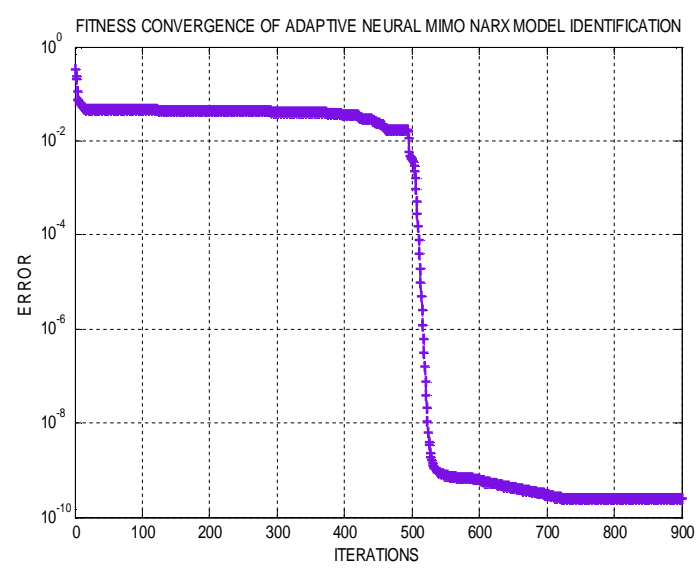

Fig.6 Fitness convergence of proposed adaptive neural-based supervisory controller identification

The last step relates to validating the resulting nonlinear adaptive models. Applying the same training diagram in Fig. 5, a good validating result demonstrates the performance of the resulting forward Neural MIMO NARX (FNMN) model which are presented in Fig.7. The error which is optimized nearly zero between the real hybrid wind-turbine supervisory control system responding reference output signals $(x, y)$ and the forward Neural MIMO NARX model responding output signals (xhat, yhat) asserts the very good performance of proposed FNMN model. Forwardly, the error shown in Fig.7 consolidates again the quality of proposed Neural MIMO NARX model.

Finally, Fig.8 illustrates the auto-tuning variation of adaptive ARX parameters of proposed forward Neural MIMO NARX Model of the hybrid wind-turbine supervisory control. Concretely, the fifteen parameters $a_{11}, a_{12}, a_{13}, b_{11}$, $b_{12}, a_{21}, a_{22}, a_{23}, b_{21}, b_{22}$ and $a_{31}, a_{32}, a_{33}, b_{31}, b_{32}$ of the two $1^{\text {st }}$ order ARX structure integrated in proposed FNMN model were adaptively autotuning as illustrated in Fig. 8. These results show that the parameters of the ARX structure integrated in proposed FNMN models now become adaptively nonlinear and will be adaptively determined from the optimized weighting values $W_{i j}$ and $w_{j l}$ of the forward Neural MIMO NARX model. This feature once more proves the proposed adaptive forward Neural MIMO NARX (FNMN) model is very powerful and adaptive in identification and in model-based advanced control as well.

In summary, Table 1 tabulates the optimized weighting values of the proposed forward Neural MIMO NARX model. The final structures of forward Neural MIMO NARX models respectively which are identified and optimized by BP learning algorithm are shown in Fig. 3. 


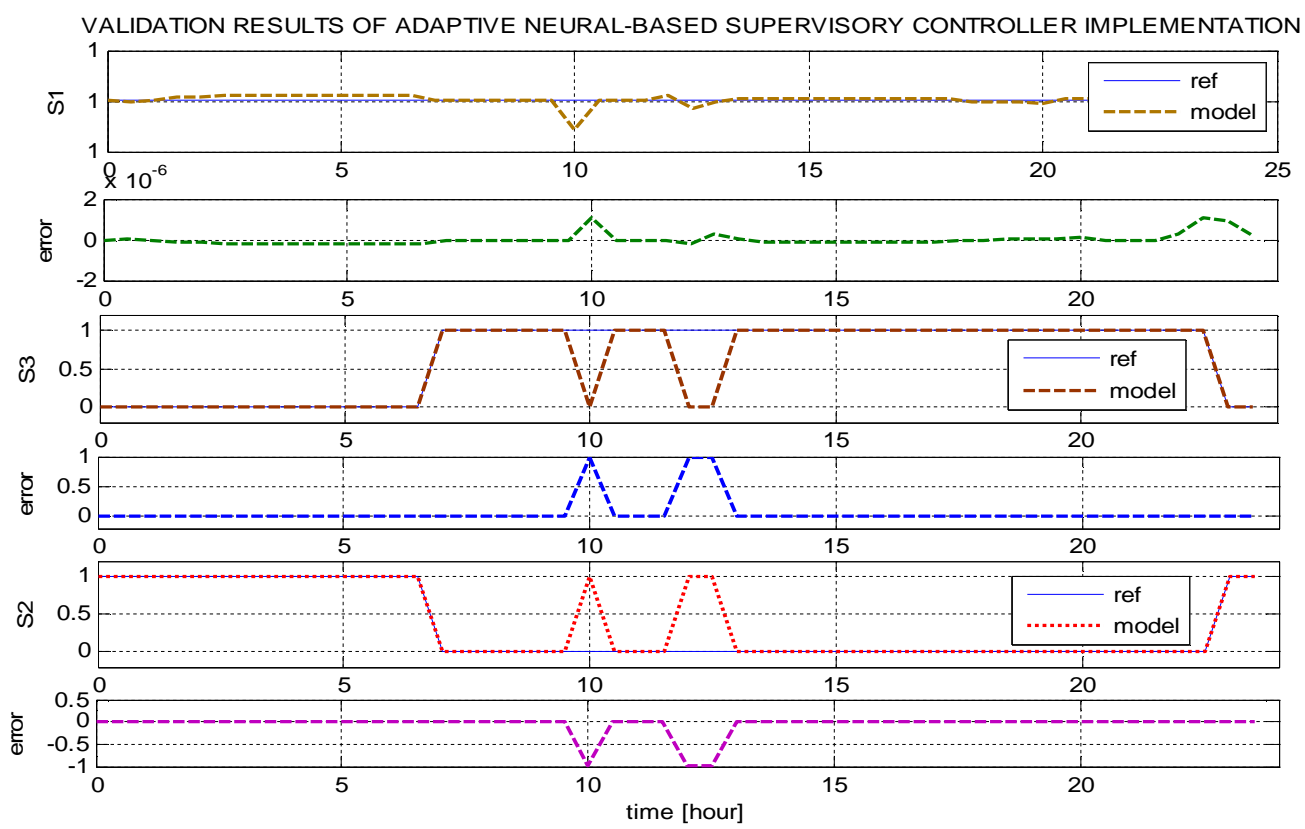

Fig.7 Validation of the proposed forward Neural MIMO NARX (FNMN) controller

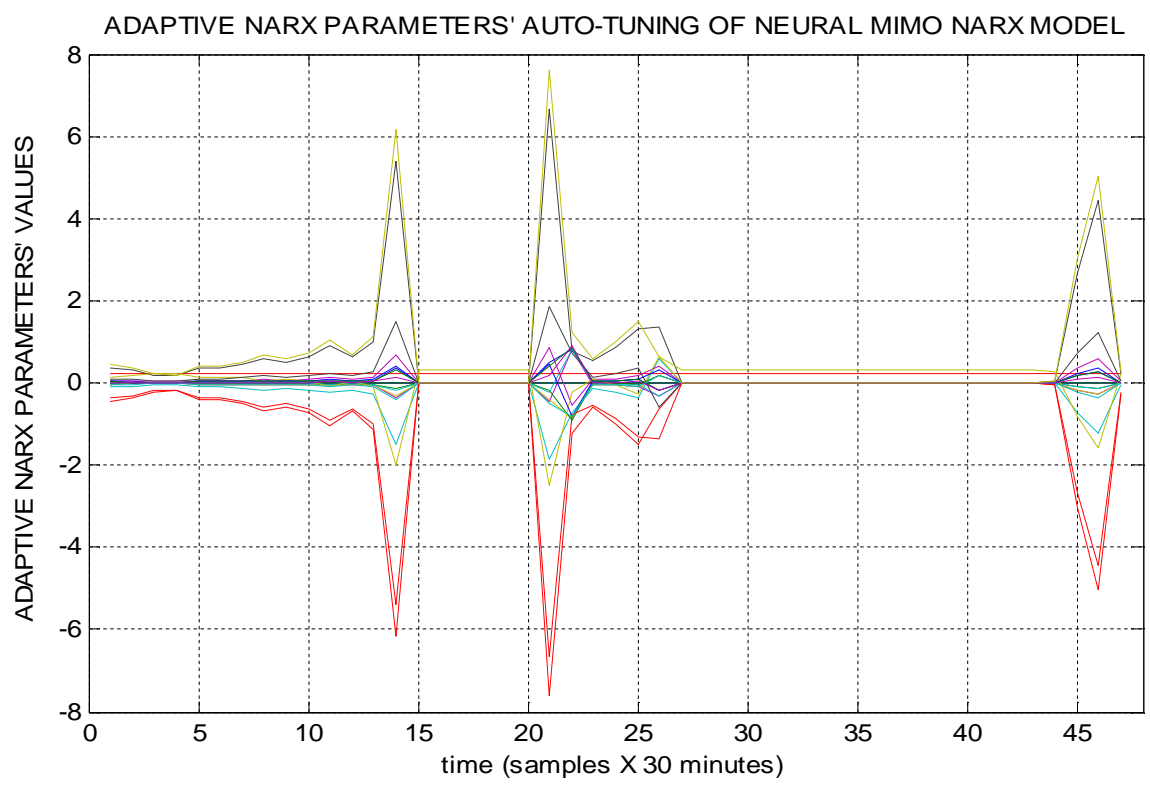

Fig. 8: Adaptive NARX parameters' auto-tuning of proposed neural MIMO NARX model 
Table 1 Optimized weights of proposed forward NEURAL MIMO-NARX - Total Number of weighting values $=68$

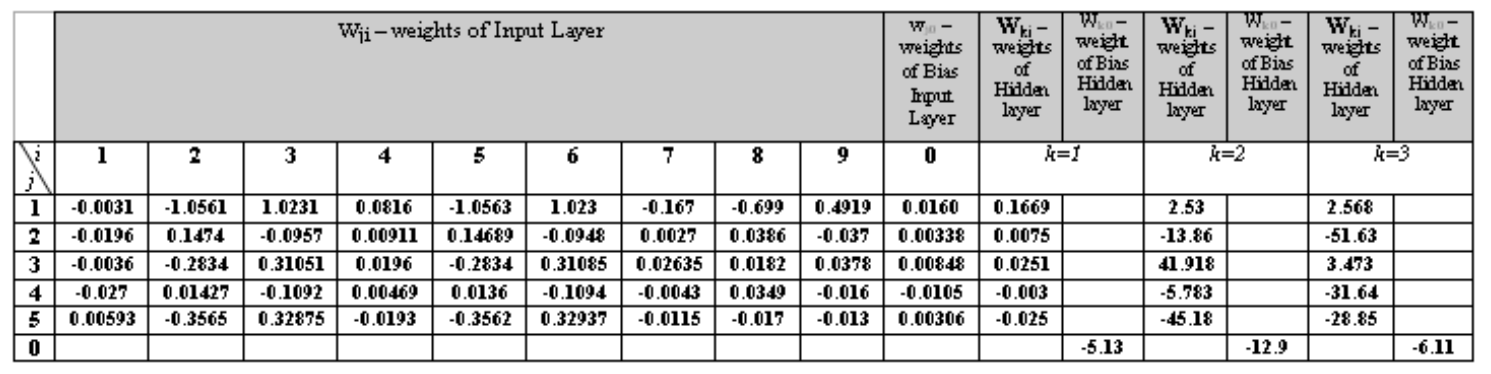

\section{CONCLUSION}

This paper investigates the novel use of proposed adaptive neural MIMO model in order to generate the supervisory controller for the hybrid wind microgrid systems. The Back Propagation (BP) learning algorithm is applied to process the experimental input-output data that is measured from the optimal desired operation of the hybrid wind microgrid systems and then to successfully optimize all nonlinear and dynamic features of this hybrid microgrid system.

\section{ACKNOWLEDGEMENT}

This research is funded by Vietnam National Foundation for Science and Technology Development (NAFOSTED) and the DCSELAB, VNU-HCM, Viet Nam. 


\section{Thiết kế bộ điều khiển giám sát hệ vi lưới hỗn hợp nguồn gió ứng dụng mô hình nơ rôn MIMO NARX thích nghi}

\section{- Hồ Phạm Huy Ánh}

- Nguyễn Ngọc Sơn

Trường Đại học Bách Khoa, ĐHQG-HCM, Việt Nam

- Trần Thiện Huân

Đại học Sư Phạm Kỹ Thuật Tp. Hồ Chí Minh, Việt Nam

\section{TÓM TÁ́T}

Bài báo khảo sát mô hình mờ nơ rôn MIMO NARX thích nghi được dùng để nhận dạng và cài đặt bộ điều khiển giám sát hệ vi lưới hỗn hợp nguồn gió. Các yếu tố phi tuyến của hệ vi lưới hỗn hợp nguồn gió sẽ được nhận dạng đầy đủ dựa trên quá trình nhận dạng thích nghi thông qua dũ liệu huấn luyện lấy từ thực nghiệm. Bài báo cũng trình bày cách khai thác thuật toán lan truyền ngược (Back-Propagation algorithm - BP) để tối ưu bộ điều khiển giám sát dùng mô hình nơ rôn NARX thích nghi. Kết quả mô phỏng cho thấy bộ điều khiển giám sát dung mô hình nơ rôn MIMO NARX thích nghi được tối ưu bởi thuật toán lan truyền ngược $B P(M P S O)$ cho tính năng và độ chính xác vượt trội.

Từ khóa: Hệ vi lưới hỗn hợp nguồn gió, thuật toán huấn luyện lan truyền ngược (BP), bộ điều khiển giám sát nơ rôn MIMO NARX thích nghi, nguồn tua-bin gió, mô hình và nhận dạng.

\section{REFERENCES}

[1]. M khan, "Supervisory hybrid control of a wind energy conversion and battery storage system," Graduate Department Of Electrical And Computer Engineering, University of Toronto, PHD thesis 2008.

[2]. M Lemmon, K He, and I Markovesky, "Supervisory hybrid systems," IEEE Control Systems Magazine, vol. 19, no. 4, pp. 42-55, 1999.

[3]. P Antsaklis and A Nerode, "Guest editorial hybrid control systems an introductory discussion to the special issue," IEEE
Transactions On Automatic Control, vol. 43, no. 4, pp. 457-460, 1998.

[4]. F Valenciaga and P Puleston, "Supervisor control for a stand-alone hybrid generation system using wind and photovoltaic energy," IEEE Transactions On Energy Conversion, vol. 20, no. 2, pp. 398-405, 2005.

[5]. M Khan and M Iravani, "Hybrid control of a grid-interactive wind energy conversion system," IEEE Transactions On Energy Conversion, vol. 23, no. 3, pp. 895-902, 2008.

[6]. C Liu, K Chau, and X Zhang, "An efficient wind-photovoltaic hybrid generation system 
using doubly excited permanent-magnet brushless machine," IEEE Transactions On Industrial Electronics, vol. 57, no. 3, pp. 831 $839,2010$.

[7]. C Wang and M Nehrir, "Power management of a stand-alone wind/photovoltaic/fuel cell energy system," IEEE Transactions On Energy Conversion, vol. 23, no. 3, pp. 957967, 2008.

[8]. D Ipsakisa, S Voutetakisa, P Seferlis, F Stergiopoulosa, and C Elmasides, "Power management strategies for a stand-alone power system using renewable energy sources and hydrogen storage," Internation Journal Of Hyderogen energy, vol. 34, no. 16, pp. 70817095, 2009.

[9]. T Gebre, T Undeland, O Ulleberg, and P Vie, "Optimal load sharing strategy in a hybrid power system based on PV/Fuel Cell/ Battery/Supercapacitor," in International Conference On Clean Electrical Power, Capri, Itali, pp. 141-146, 2009.

[10].W Irena et al., "A power-quality management algorithm for low-voltage grids with distributed resources," IEEE Transactions On Power Delivery, vol. 23, no. 2, pp. 1055-1062, 2008.

[11].S Teleke, M Baran, A Huang, S Bhattachar, and L Anderson, "Control strategies for battery energy storage for wind farm dispatching," IEEE Transactions On Energy Conversion, vol. 24, no. 3, pp. 725-732, 2009.

[12].S Daniel and N Gounden, "A novel hybrid isolated generating system based on PV fed inverterassisted wind-driven induction generators," IEEE Transactions On Energy Conversion, vol. 19, no. 2, pp. 416-422, 2004.

[13].L Krichen, A Ouali, and G Boukettaya, "Fuzzy logic supervisor for power control of an isolated hybrid energy production unit," International Journal of Electrical and Power Engineering, vol. 1, no. 3, pp. 279-285, 2007.

[14].E El Mokadem, V Courtecuisse, and C Saudemont, "Fuzzy logic supervisor-based primary frequency control experiments of a variable-speed wind generator," IEEE Transactions on Power Systems, vol. 24, no. 1, 2009.

[15].G Cimuca, C Saudemont, B Robyns, and M Radulescu, "Control and performance evaluation of a flywheel energy-storage system associated to a variable-speed wind generator," IEEE Transactions On Industrial Electronics, vol. 53, no. 4, pp. 1074-1085, 2006.

[16].C Abbey and G Joos, "Supercapacitor energy storage for wind energy applications," in $40^{\text {th }}$ Annual Meeting Of The IEEE-IndustryApplications-Society, vol. 43, Hong Kong, China, pp. 769-776, 2007.

[17].M Datta, T Senjyu, A Yona, and T Funabash, "A fuzzy control based coordinated method for isolated power utility connected clustered photovoltaic systems to provide frequency control," in IEEE 15th International Conference On Intelligent System Applications To Power Systems, Curitiba, Brazil, pp. 1-6, 2009.

[18].L Krichen, B Francois, and A Ouali, "A fuzzy logic supervisor for active and reactive power control of a fixed speed wind energy conversion system," Electric Power Systems Research, vol. 78, no. 3, pp. 418-424, 2008.

[19].R Welch and G Venayagamoorthy, "Optimal control of a photovoltaic solar energy system with adaptive critics," in IEEE International Joint Conference On Neural Networks, vol. 16, Orlando, USA, pp. 985-990, 2007. 